\title{
Comparison of Blast Analysis Methods for Modular Steel Structures
}

\author{
Bülent ERKMEN ${ }^{1}$
}

\begin{abstract}
Two blast analysis methods widely used are three-dimensional finite element (FE) and uncoupled equivalent single degree of freedom (ESDOF) methods. The uncoupled equivalent ESDOF method, which is the most common blast analysis method, provides considerable advantages and simplicity in analysis and design stages. However, the inherent assumptions and simplifications involved but especially neglecting member's dynamic interactions can significantly affect accuracy of analysis results. In this study, blast performance of a prototype two-module steel blast-resistant building is evaluated using uncoupled ESDOF and FE methods. The results are compared to evaluate adequacy of uncoupled ESDOF method for blast analysis of the structure.
\end{abstract}

Keywords: Blast loads, blast-resistant steel modular buildings, equivalent single degree of freedom, dynamic interaction.

\section{INTRODUCTION}

Due to growing terror threat and accidental explosions, blast performance of structures is becoming an important structural design consideration for not only military structures but also for structures at petrochemical industry and industrial plants to ensure safety and protection of the workforce. Blast loads, which are typically ignored in the design of structures, have effects including but not limited to structural damage, personal casualties, and social and economic impacts. Especially, the terror attacks on the Oklahoma City Federal and World Trade Center buildings, which resulted in total building collapse and massive loss of lives, have attracted the attention of many researchers to improve blast resistance of structures [1,2,3]. Although blast events are increasingly encountered in Turkey [4] (as well as the rest of the world), there is no regulation or guideline that concerns design principles and guides for engineers on the blast design and analysis.

The primary design objective for structures subjected to blast loading is to ensure structural integrity and thereby preventing or limiting loss of lives [2,5,6]. Unless the structure is very critical, it is not economical and practical to ensure that the deformations and structural

\footnotetext{
Note:

- This paper has been received on July 23, 2016 and accepted for publication by the Editorial Board on January 30, 2018.

- Discussions on this paper will be accepted by May 31, 2018.

- DOI: 10.18400/tekderg.389954

1 Ozyegin University, Department of Civil Engineering, İstanbul, Turkey - bulent.erkmen@ozyegin.edu.tr
} 
damage remain within elastic limits for an unlikely blast event. Therefore, deformations occurring in structural components under blast loads are allowed to be beyond linear elastic limits (i.e., plastic deformation) to minimize the cost. Therefore, blast damage is typically measured in terms of deformations instead of internal loads (e.g., shear, moment) as would be done in seismic design. Different blast damage levels and corresponding deformation limits are given by FEMA [2], ASCE [5], and US Army Corps of Engineer [7].

For blast analysis, there are two widely used nonlinear dynamic analysis methods. These are three-dimensional (3D) finite element (FE) and uncoupled equivalent single degree of freedom (ESDOF) analysis methods. In addition, there are also tools consisting of simple graphical solutions, empirical formulas, and closed-form solutions [3]. However, these simple methods are generally based on the ESDOF analysis method, applicable for special conditions, and provide limited information for blast performance of structural members $[2,5]$. The $3 \mathrm{D}$ finite element method is the most suitable and reliable analysis method for determining blast performance of structural members. With FE analysis method, the overall structural behavior under blast loads can be determined since the whole structural system is modeled. In addition, the dynamic interaction of structural members, the effects of geometric nonlinearity (e.g., membrane action and second order effects), and nonlinear material behavior can be included. With this method, the progressive formation of plastic hinges, their location, and plastic hinge propagation along structural members can be captured, and their effects on deflection, ductility, and support plastic rotation can be included. Mass and mass distribution over the structure are other important parameters that affect blast analysis results. Because all structural members are included in the FE model, achieving realistic mass distribution within the structure is possible. Blast loads are surface pressures acting on outer surfaces of structures, and hence with realistic FE models it is possible to achieve more realistic blast load distribution over the structure. In conclusion, FE blast analysis method is a reliable and powerful approach, and it has been shown that blast performance of structural members (damage level, ductility, and support plastic rotations) determined using FE approach is reliable and consistent with experimental results [5,8,9]. However, the need for high-performance computers to solve millions of equilibrium equations, high costs of $\mathrm{FE}$ software, and the need for well-trained and experienced engineers to build models, select and perform the appropriate analysis method, and interpret the results are significant disadvantages of the FE method for blast analysis.

Because of the disadvantages of the FE method, the uncoupled equivalent single degree of freedom blast analysis method is usually preferred at the preliminary design stage and for structures with simple lateral and vertical load resisting systems, or structures that are not considered to be critical in terms of blast performance. The ESDOF analysis method is also known as simplified spring analysis method, and it is commonly used because of its simplicity and relatively modest computational resources required. Because the ESDOF method is easy and simple compared to the FE method, it is widely used to determine structural damage due to blast loading [1,5,10]. For example, the ESDOF method is used by the United States Army Corps of Engineers in blast design and evaluation of critical military structures. In addition, the blast software SBEDS developed by this army unit is based on the ESDOF method, and it is widely used by representatives of U.S. Government Agencies and their contractors as a reliable blast analysis tool [7]. 
The ESDOF blast analysis method is a dynamic analysis method that gives approximate results $[5,8,11]$. The ESDOF method provides considerable advantages and simplicity in blast analysis and design of structures. However, the assumptions and simplifications involved can significantly affect the accuracy of analysis results. In the ESDOF analysis, the dynamic interaction of structural members is ignored (i.e., uncoupled). In other words, the deformation compatibility of structural members and internal force balance at their connections are neglected and violated. Biggs [12] showed that the dynamic interaction of structural members can be neglected when the ratio of natural vibration frequencies of interconnected elements is at least two. However, the study was performed on a rather limited number of structural element, boundary condition, and blast loading. Baker et al. [13] showed that the ESDOF analysis is an approximate but on the safe side analytical method based on the work performed on two-degree of freedom systems with a limited number of parameters.

Although the ESDOF method is widely used throughout the engineering community, and it is considered to yield conservative results compared to the FE blast analysis method, there is no comparative detailed study on the accuracy and reliability of the ESDOF blast analysis method. In this study, damage levels of vertical and lateral load-resisting systems of a twomodule blast-resistant steel-framed structure were determined using three-dimensional FE and ESDOF blast analysis methods. The analysis results are compared to evaluate the adequacy of the uncoupled ESDOF blast analysis method.

\section{PROTOTYPE MODULAR STEEL STRUCTURE}

Figure-1 shows a typical three-module blast-resistant modular steel-framed (BMS) structure during and after installation. The BMS structures are recognized as an economical and practical solution to minimize blast effects and are valuable assets for protection of personnel involved in activities located near potential explosion sites [5,6]. These structures are widely used as control rooms, office buildings, and living quarters in areas with a high risk of explosion, fire, or danger from toxic materials in petrochemical industry, and temporary living shelters in military areas.
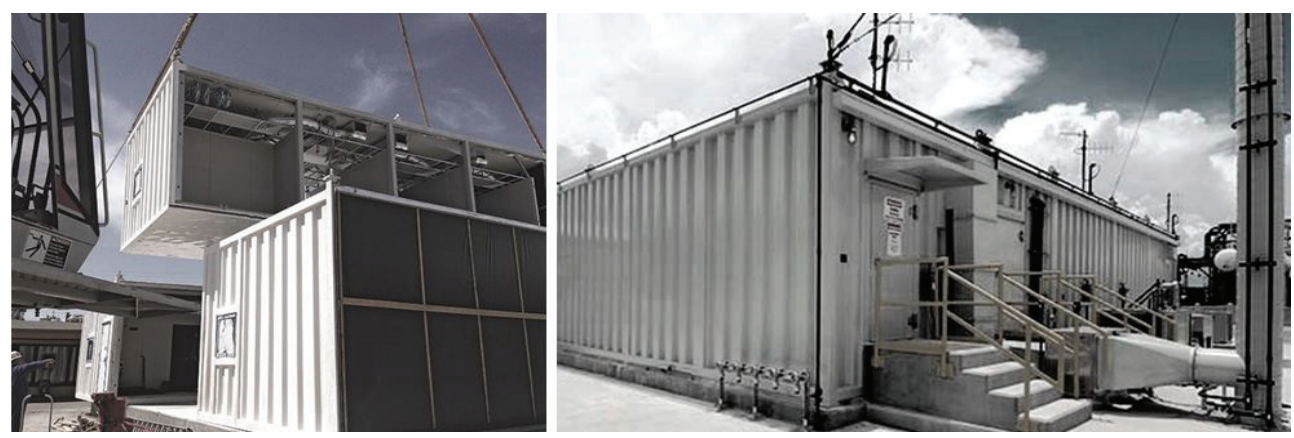

Figure 1. Blast-resistant modular steel-framed (BMS) building with three modules 
The prototype BMS structure studied consists of two modules, each with a length of $12 \mathrm{~m}$, width of $3 \mathrm{~m}$, and $3.5 \mathrm{~m}$ height. The building floor and elevation plans are given in Figure-2 through 4 . The joints and connections are designed to develop full plastic capacities of the connected members. In addition, the connection between the modules is assumed to be strong enough to ensure full load transfer between the modules under blast loads. The vertical openings between the steel frame members (i.e., column and beam) are closed with crimped wall panels as shown in Figure-3 and Figure-4. Flat steel plates supported by the roof and floor joists are used to cover the roof and floor openings. In addition, diaphragm struts are used at two bays both on the roof and floor to strengthen their diaphragms as shown in Figure2.

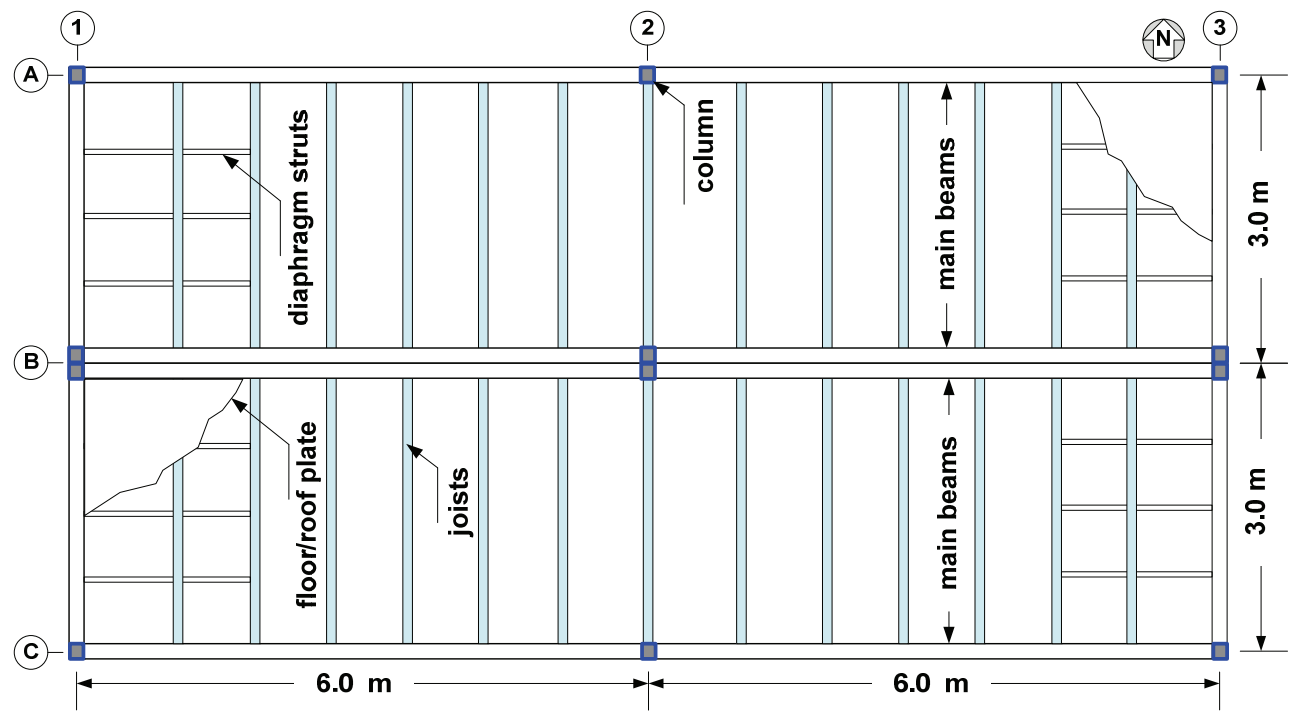

Figure 2. Prototype building floor and roof plans

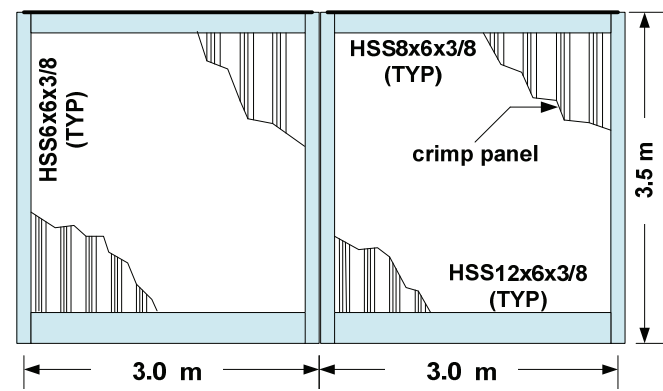

(a)

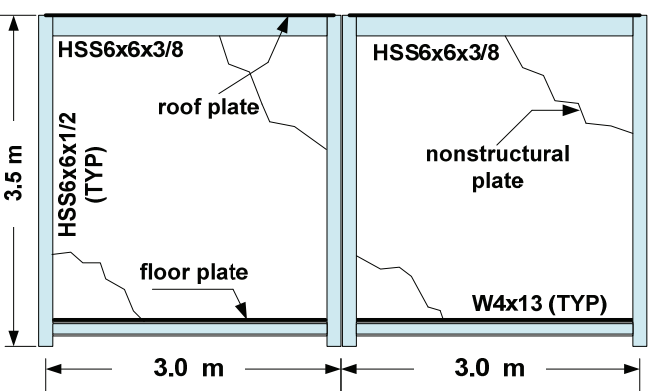

(b)

Figure 3. Prototype building elevation views at (a) column axes 1 and 3 (b) column axis 2 


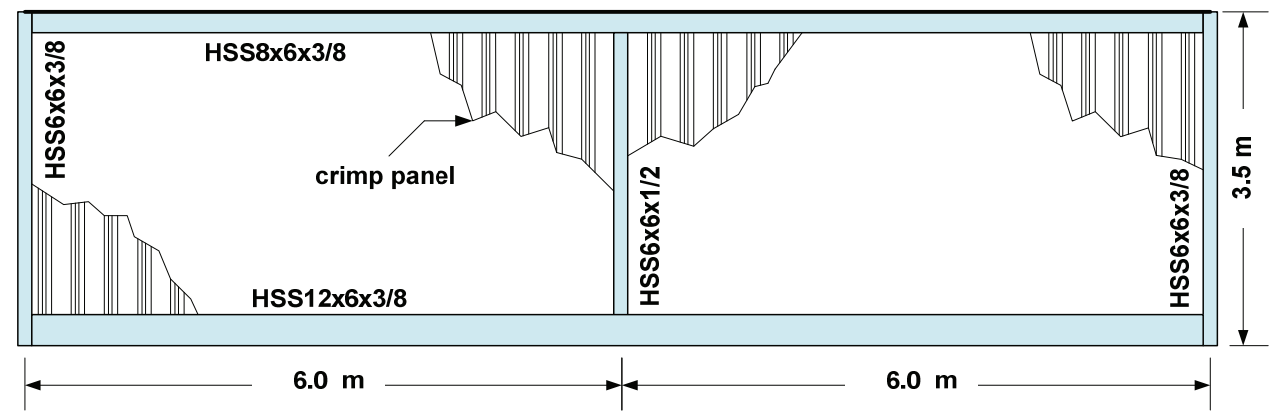

(a)

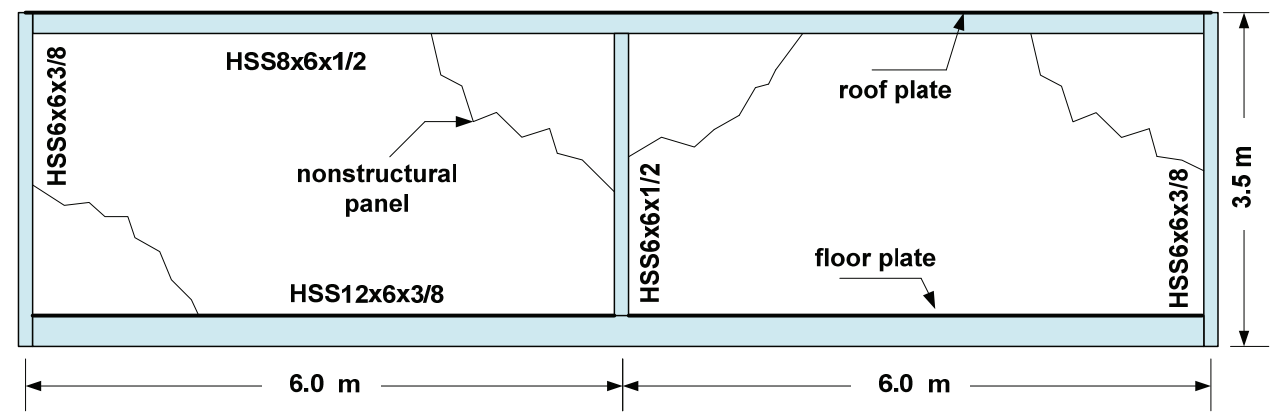

(b)

Figure 4. Prototype building elevation views at (a) column axes $A$ and $C$ (b) column axis $B$

All structural sections used for the prototype building are AISC-360 (American Institute of Steel Construction) [14] hollow structural sections (HSS). The only exception is the W4x13 I-beam section, which is used for floor and roof joists. The structural elements were selected to be seismically compact per AISC-341 [15] about both their weak and strong bending axes to ensure that local buckling and instability failures do not occur before the full plastic bending capacity of the sections is achieved. The connections between the structural sections are assumed to be continuous weld type and strong enough to develop the full capacities of the connected members. The wall, floor, and roof plates are assumed to be attached to the frame members by continuous welds as well.

The prototype building wall panels are crimped (trapezoidal cross-section) steel plate while the floor and roof are covered with flat steel plates. The wall panels are generally the most critical structural elements for blast loading because the blast load is the largest on the surfaces directly facing the blast. Despite the ease of connecting flat steel wall panels to the frame elements, these panels are not generally preferred due to their limited ductility capacity. Crimped steel wall panels, which have much higher ductility, are therefore preferred for the walls. The sections of steel frame elements used for the prototype building and the associated AISC steel grades are given in Table-1. 
Comparison of Blast Analysis Methods for Modular Steel Structures

Table 1. Prototype building steel frame members, steel grades, and sections

\begin{tabular}{|c|c|c|}
\hline Frame Member & Steel Grade & Section \\
\hline Corner columns (total of 8) & A500 Gr. B & HSS $6 \times 6 \times 3 / 8$ \\
\hline Other columns (total of 4 ) & A500 Gr. B & HSS6x6x1/2 \\
\hline Top perimeter longitudinal main beams (total of 2 ) & A500 Gr. B & HSS $8 \times 6 \times 3 / 8$ \\
\hline Top intermediate longitudinal main beams (total of 2) & A500 Gr. B & HSS $8 \times 6 \times 1 / 2$ \\
\hline Top perimeter transverse main beams (total of 4 ) & A500 Gr. B & HSS $8 \times 6 \times 3 / 8$ \\
\hline Top intermediate transverse main beams (total of 2 ) & A500 Gr. B & HSS $6 \times 6 \times 3 / 8$ \\
\hline Bottom longitudinal main beams (total of 4 ) & A500 Gr. B & HSS $12 \times 6 \times 3 / 8$ \\
\hline Bottom transverse main beams (total of 4 ) & A500 Gr. B & HSS $12 \times 6 \times 3 / 8$ \\
\hline Roof and floor joists & A992 Gr. 50 & W4x13 \\
\hline Roof and floor diaphragm struts at module ends & A500 Gr. B & $\mathrm{HSS} 3 \times 2 \times 3 / 16$ \\
\hline Roof and floor steel plate & $\mathrm{A} 36$ & $5 \mathrm{~mm}$ thick \\
\hline Crimped steel wall plate & A36 & $\begin{array}{l}5 \mathrm{~mm} \text { thick and } \\
100 \mathrm{~mm} \text { deep }\end{array}$ \\
\hline
\end{tabular}

\subsection{Blast Damage Levels and Deformation Limits}

Blast performance of structures is generally expressed in terms of damage experienced by its structural members. Under blast loading, the structural members are allowed to deform beyond their elastic limit and yield point to achieve an economic design. In other words, the structural members are expected to exhibit plastic behavior with significant post-yielding deformations but without failure. Therefore, the maximum stress levels experienced by the structural members are not good indication of blast damage. In blast design and evaluation of structural members, their adequacy is judged based on the maximum deformation and support rotation (i.e., hinge rotation) $[1,5]$. Generally, the maximum deformation of structural members is expressed in terms of ductility ratio $(\mu)$. Ductility, which is defined as the ratio of maximum displacement experienced by the member to the displacement corresponding to its elastic limit, is a good indication of plastic deformations and structural damage. Support rotation $(\theta)$ is another measure of structural damage, and it is a good indication of instability present in critical areas of frame members [5]. However, the support rotation is not directly the joint rotation at the support, but rather it is defined as the angle formed between a line connecting the supports and a line between the support and the point of maximum deflection [5].

The structural damage caused by blast loading is usually characterized as low, medium, or high damage. At the low damage level, the building is expected to remain functional with some local damage, but moderate repairs are expected to restore the integrity of the structure envelope. At medium damage level, widespread building and component damage is expected with significant cost of repair before the building can be reoccupied. At high damage level, significant damage is permitted up to the point of failure, but the structure is expected to remain intact. The allowable response (i.e., ductility and support rotation) of individual frame components for these three damage levels are given in Table- 2 for the prototype building. The limits on maximum ductility and support rotation are based on the type of frame element, 
construction material, location of frame element within the structure, and the selected damage level.

Table 2. Damage levels and corresponding maximum ductility and support rotations [5]

\begin{tabular}{|l|c|c|c|c|c|c|}
\hline \multirow{2}{*}{ Structural Element Type } & \multicolumn{6}{|c|}{ Blast Response Range } \\
\cline { 2 - 8 } & \multicolumn{2}{|c|}{ Low Damage } & Medium Damage & \multicolumn{2}{c|}{ High Damage } \\
\cline { 2 - 7 } & $\mu$ & $\theta$ & $\mu$ & $\theta$ & $\mu$ & $\theta$ \\
\hline Crimped wall panel & 2.5 & 1.5 & 5.0 & 3.0 & 10.0 & 6.0 \\
\hline Floor and roof steel flat plates & 5.0 & 3.0 & 10.0 & 6.0 & 20.0 & 12.0 \\
\hline Primary steel frame members & 1.5 & 1.0 & 2.0 & 1.5 & 3.0 & 2.0 \\
\hline Other beams (joists) & 3.0 & 2.0 & 10.0 & 6.0 & 20.0 & 12.0 \\
\hline
\end{tabular}

\subsection{Material Behavior at High Strain Rates}

To determine damage levels for structures and structural elements under rapidly applied loads such as blast loading, the mechanical behavior of construction materials at high strain rates should be employed. The static properties of steel grades available from standards and codes are the minimum mechanical properties. However, in practice, the average yield strength of steel used for structural elements is approximately $25 \%$ greater than the specified minimum values $[5,16]$. A strength increase factor (SIF) is used to account for this extra static strength to reduce conservatism and make use of section full available capacity for blast loading. The SIF values used for the structural elements of the prototype building are given in Table- 3 for different stress types and steel grades.

Table 3. Strength and dynamic increases factors and dynamic yield strength [5]

\begin{tabular}{|c|c|c|c|c|c|c|}
\hline Steel Grade & $\begin{array}{c}\text { Static Yield } \\
\text { Stress, } F_{y} \\
(\mathrm{MPa}) \\
\end{array}$ & $\begin{array}{l}\text { Min. Tensile } \\
\text { Strength, } F_{u} \\
\quad(\mathrm{MPa})\end{array}$ & SIF & Stress Type & DIF & $\begin{array}{c}\text { Dynamic } \\
\text { Yield Stress, } \\
\boldsymbol{F}_{d y}(\mathrm{MPa})^{(1)}\end{array}$ \\
\hline \multirow{2}{*}{$\begin{array}{l}\text { ASTM A-36 } \\
\text { Gr. } 36\end{array}$} & \multirow{2}{*}{248} & \multirow{2}{*}{400} & \multirow{2}{*}{1.1} & Bending and Shear & 1.29 & 352 \\
\hline & & & & Axial & 1.19 & 325 \\
\hline \multirow{2}{*}{$\begin{array}{l}\text { ASTM A500 } \\
\text { Gr. B }\end{array}$} & \multirow{2}{*}{317} & \multirow{2}{*}{400} & \multirow{2}{*}{1.21} & Bending and Shear & 1.10 & 422 \\
\hline & & & & Axial & 1.10 & 422 \\
\hline \multirow{2}{*}{$\begin{array}{l}\text { ASTM A992 } \\
\text { Gr. } 50\end{array}$} & \multirow{2}{*}{345} & \multirow{2}{*}{448} & \multirow{2}{*}{1.1} & Bending and Shear & 1.19 & 452 \\
\hline & & & & Axial & 1.12 & 425 \\
\hline
\end{tabular}

(1) $F_{y d}=F_{y}(S I F \times D I F)$

Under dynamic loads such as blast loading, concrete and steel materials cannot respond at the same rate at which the load is applied to the structure. The yield strength of these materials increases under rapidly applied blast loads due to high strain rate. This increase in the yield 
strength can be significant for lower strength materials and decreases as the material static yield strength increases $[2,5,10,12,13]$. To incorporate the effect of strain rate on material mechanical behavior, a dynamic increase factor (DIF), which is simply the ratio of dynamic material strength to its static strength, is typically applied to the static strength values. The appropriate DIF values are functions of material type, strain rate, and type of stress $[5,16]$. The DIF values recommended for the prototype building and the corresponding dynamic yield strength values used in the blast analyses are given in Table- 3 for different loading conditions. In the performed dynamic analyses, elastic-perfectly plastic material models were used with yield strength equal to the dynamic yield strength.

\section{BLAST LOADS FOR THE PROTOTYPE BUILDING}

Blast loads that are mentioned here are explosion loads occurring in the petrochemical industry due to vapor cloud and dust explosions, and do not include blast and fragment dissipations caused by bombs, mortars and rockets. At the time of explosion, a sudden release of energy in the form of atmospheric shock or pressure wave occurs [3]. The explosive material is converted to very hot, dense, and high-pressure gas expanding at very high speeds. Depending on the type of explosive material, two characteristic shapes of blast waves known as shock waves and pressure waves are distinguishable. The shock and pressure waves are generated when the explosive material is a condensed material (liquid or solid) or vapor cloud, respectively. The shock waves cause an almost instantaneous rise from atmospheric pressure to a peak pressure known as free-field, peak side-on or incident, overpressure $\left(P_{s o}\right)$. As the wave front expands, the pressure starts to decrease rapidly with distance and time to ambient pressure, and a negative pressure phase occurs as shown in Figure-5 [1]. The wave has a very brief span of existence, measured typically in thousandths of a second. When the explosive material is vapor cloud, the blast creates pressure waves. The pressure waves increase ambient pressure relatively slowly, reach the ambient pressure more slowly, and do not create a negative pressure wave as shown in Figure-5.

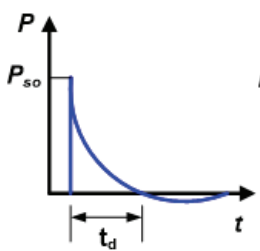

(a)

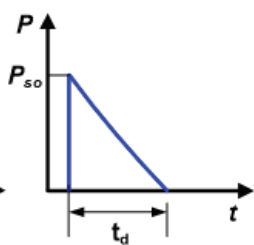

$t_{d}$

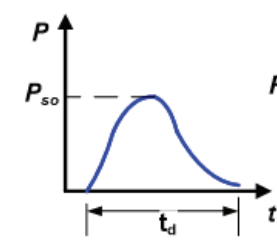

(b)

Figure 5. Characteristic and idealized shapes of (a) shock waves (b) pressure waves

Blast load pressure-time data resulting from common explosions in the petrochemical industry are difficult to precisely determine due to uncertainties regarding type and quantity of the explosive material and location of explosion. In addition, the interaction of blast wave with topography and structure geometry is quite complex $[5,17]$. Although the interaction between the blast wave and structures can be incorporated using computational fluid 
dynamics (CFD), such analyses are quite complex and not economical. Therefore, usually simpler closed-form solutions are preferred to determine blast loads acting on different sides of structures if the structure geometry is not complex, and the structure is not very critical [5].

Typical blast peak side-on overpressure due to explosions occurring in petrochemical industry is between $10-100 \mathrm{kPa}$ with a positive phase duration $\left(t_{d}\right)$ between $20-200 \mathrm{~ms}$ [5]. In this study, two different explosion scenarios corresponding to moderate and high damage levels of the prototype building were selected. These are blast loading with a free-field overpressure of $50 \mathrm{kPa}$ (BL-50) and $80 \mathrm{kPa}$ (BL-80) corresponding to medium and high damage levels of the building, respectively. It was assumed that the positive duration of both blast scenarios is $140 \mathrm{~ms}$, and the explosion source is on the north side of the building with the pressure wave approaching the building from its broadside.

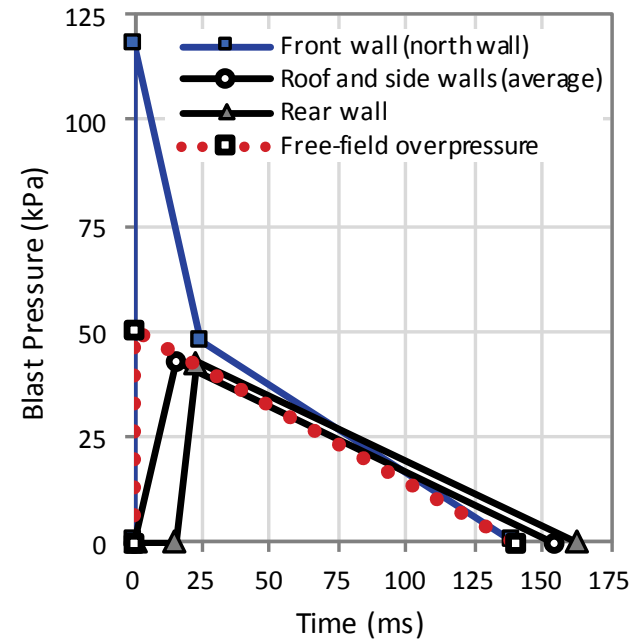

(a)

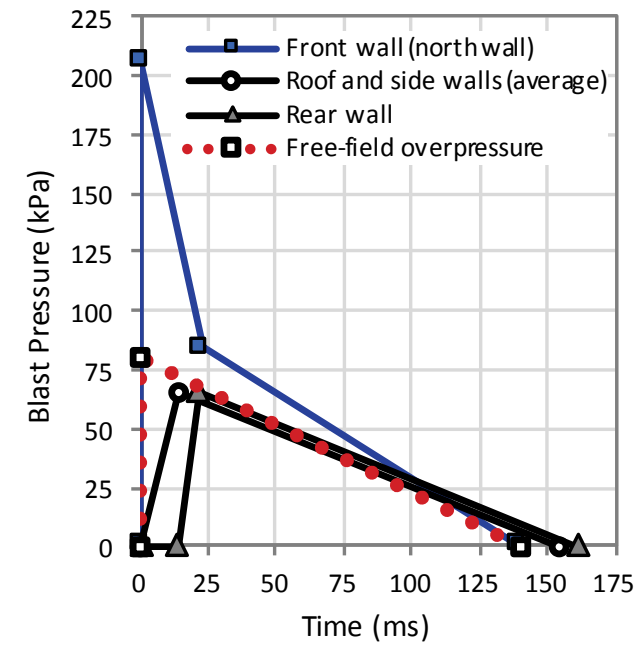

(b)

Figure 6. Free-field and local pressures on walls for (a) blast BL-50 and (b) blast BL-80

When the incident pressure wave impinges on a structure, it is reflected and reinforced, producing what is known as reflected pressure $\left(P_{r}\right)$. The reflect pressure is always greater than the incident pressure and varies with the angle of incidence of the blast wave. In other words, the reflected blast pressure is different for each surface of the building such as front wall, side walls, rear wall, and roof. For example, the reflected pressure on a surface that is perpendicular to the direction of the blast wave will experience the maximum reflected pressure, which is approximately twice the free-field overpressure. In this study, a simplified method proposed by ASCE [5] was used to determine pressure-time blast curves acting on different surfaces of the prototype building for each blast scenario. In other words, free-field overpressure was converted into local pressure loads for the prototype building front, side walls, rear wall, and roof by approximating the complex interaction between the blast 
Comparison of Blast Analysis Methods for Modular Steel Structures

pressure wave and building geometry. For the two blast scenarios, time-pressure curves acting on the walls and roof of the building are given in Figure-6. As the explosion wave propagates along the roof and side walls, the pressure on these surfaces decreases. However, the change in pressure along the side walls and roof was not taken into consideration since the prototype structure width is small compared to the speed of the blast wave.

\section{BLAST ANALYSIS METHODS}

Blast performance of the prototype building under the blast scenarios was determined using finite element (FE) and uncoupled equivalent single degree of freedom (ESDOF) analysis methods. With the FE method, the overall blast performance of the structure was determined including dynamic interaction of structural members. Because the FE method is a standard structural dynamic analysis method, it is briefly summarized in the following section for the prototype building. The fundamentals of ESDOF blast analysis method and how to apply the method to determine blast performance of individual structural members is given in the following sections with several examples.

\subsection{Finite Element Blast Analysis Method}

ABAQUS 6.14 general-purpose program was used for the FE blast analysis of the building. The developed three-dimensional (3D) building FE model, which is shown in Figure-7, consisted of approximately 40,000 nodes and 38,500 elements. All beams and columns were modeled using the B31 beam element, which is suitable for thick (stout) as well as slender beams. The element is a Timoshenko (shear flexible) beam allowing transverse shear deformation. The S4R shell element, which is a 4-node, quadrilateral element with reduced integration and large-strain formulation, was used for roof and floor plates and wall crimped panels. A nominal mesh size of $300 \mathrm{~mm}$ was used for all elements. The building was assumed to be anchored to its foundation at nine anchorage points located under the columns as shown in Figure-7. The anchorage points were represented by pinned boundary condition. Elasticperfectly plastic material model was used in the analysis, and both material SIF and DIF factors were considered for the dynamic yield stresses. Both material and geometric nonlinearities (membrane action) were considered. The bending stiffness of the plates (roof, floor, and walls) is very small since plates thickness is very small. Therefore, the loads are mainly resisted by in-plane membrane action of the plates [18]. This mechanism was included in the model by including effects of geometric nonlinearity for the shell elements. The only loads considered for the analysis are the building self-weight and the blast loads. The building blast performance was computed in two analysis steps, namely static and subsequent implicit dynamic analysis steps, in which building self-weight and blast loads were applied, individually. 

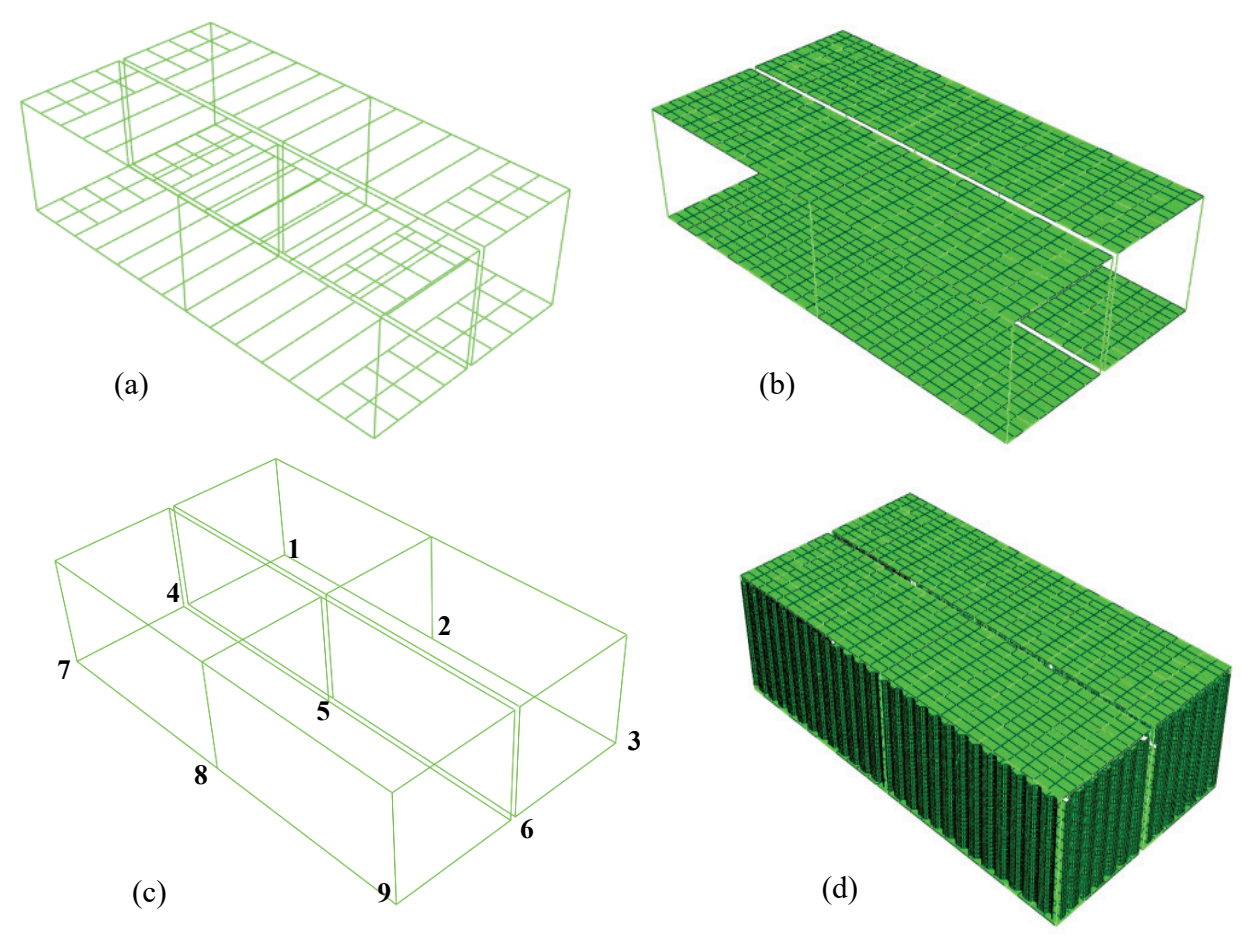

Figure 7. Prototype building FE model (a) beams and columns, (b) floor and roof plates, (c) anchors and (d) whole model

\subsection{Uncoupled Equivalent Single Degree of Freedom Blast Analysis Method}

The uncoupled equivalent single degree of freedom system is also known as simplified spring model since the point mass can only move along one axis. Because of its simplicity, being user friendly and requiring few input parameters, the ESDOF method is widely used to determine dynamic behavior of structural members subjected to blast loads. The ESDOF method is usually favorable because of its simplicity however this simplicity also leads to inaccurate analysis results. Therefore, the ESDOF analysis method is considered as a blast analysis method that gives approximate but also conservative results [5,8,12].

Because the dynamic behavior of structural elements is computed independently (i.e. uncoupled) in the ESDOF analysis, the dynamic interaction of interconnected elements (e.g., columns, beams, and plates) is neglected. In other words, the deformation compatibility and internal dynamic load equilibrium at member joints are neglected in the ESDOF analysis. Studies on effects of dynamic interaction of interconnected structural elements on ESDOF results are very limited. Biggs [12] showed that dynamic interaction of interconnected structural members could be neglected for two degrees of freedom systems where the ratio of natural vibration frequencies of the connected elements is at least two. However, the systems studied were rather simple with an elastic beam supported by elastic girders at each support. Blast loads were considered only for the beam while no direct blast load was 
considered for the girders. Baker et al. [13] performed dynamic analysis on two-degree of freedom systems with limited range of variables and showed that the ESDOF approach is conservative. Lawver et al. [11] using experimental results on individual steel columns showed that the ESDOF method is unable to predict blast performance of steel columns for close or large blast charges. However, in the developed ESDOF models, the effects of local bending of column web and flanges were neglected, and this is the main reason for the reported observations. Krauthammer [8] attributes the greatest weakness of the ESDOF to lack of information on the treatment of fully nonlinear systems by the ESDOF simulations.

In any elastic-perfectly plastic ESDOF model, there are four parameters controlling the dynamic behavior and results of the analysis. These are blast load, system damping force, capacity of plastic hinges (yielding level or resistance), and natural vibration period, which depends on spring stiffness and concentrated point mass. The blast load applied to the ESDOF system of a structural member is determined as the product of blast pressure and its tributary surface area. The tributary blast surface area is defined as the area computed by dividing the total static load carried by the member to the uniform static pressure applied to the building side (wall or roof) where that member is located. Typically, good engineering judgment is required in lieu of rigorous mathematical procedures to determine tributary area and blast load for each individual structural member.

Another important parameter for the ESDOF blast analysis is the spring load-deflection relationship, which is also known as the resistance-curve. Because the ESDOF system has only one displacement degree of freedom, this displacement is selected to correspond to the displacement of the structural member at the point of maximum response such as a plastic hinge location. To determine load-deflection relationship for the ESDOF system, the location of maximum deflection, plastic hinge locations, its formation sequence, and capacities should be determined for the structural member. For example, the ESDOF systems corresponding to the beam shown in Figure-8 with fixed support condition will have the maximum deflection at the mid-span when subjected to uniform blast loading. The corresponding resistance-curve will have three different stiffness values. The location of plastic hinges, stiffness values, and the corresponding loads (resistance) can be determined by applying a distributed static load with the same distribution as the blast load and increasing it until failure. Readily available tables defining resistance-curves for beams with different boundary conditions, column, and plates are available in the literature [12].
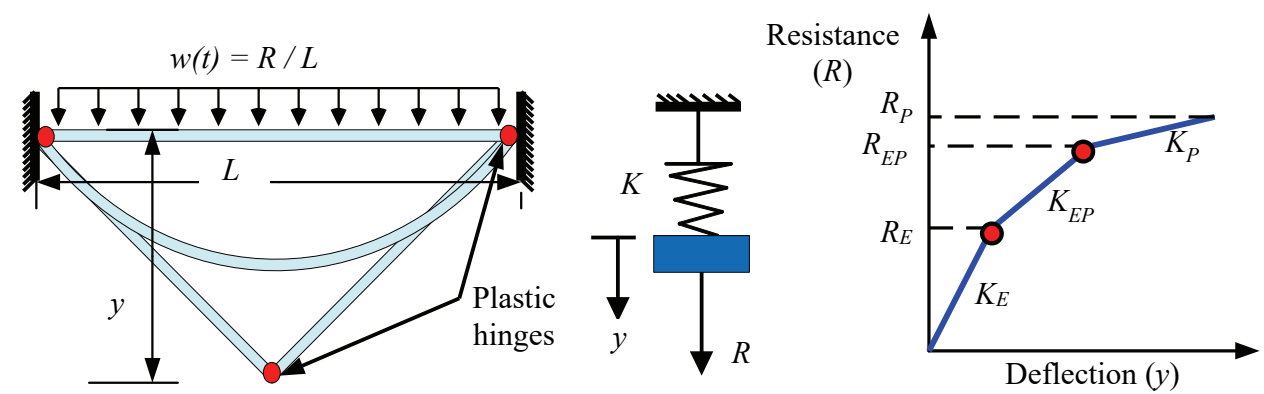

Figure 8. Plastic hinges for a beam with fixed supports and force-displacement relationship for the corresponding ESDOF system 
Another parameter affecting the dynamic behavior of ESDOF system is the point mass attached to the spring. This mass includes the self-weight of the structural member, weight of permanently attached equipment if any, and an estimate of the mass located over the tributary blast area and riding along with the member. However, the concentrated mass of ESDOF system is actually distributed over the tributary blast area of the structural member, and the velocity, acceleration, and displacement histories are different for any point on the tributary area. Additional error is introduced into the ESDOF analysis results by assuming that the blast load is a concentrated load applied at the point of maximum deflection. Therefore, ESDOF systems set up as described does not have the same work, strain and kinetic energies at any given time as the actual structural member, and it cannot be used to accurately predict the blast performance (i.e., displacement) of the structural member. In order to match the displacement histories computed using the ESDOF and actual structural member, effective mass, force, and resistance terms are used for the ESDOF system [12]. The dynamic motion of an ESDOF system is given by

$M \ddot{y}(t)+c \dot{y}(t)+K y(t)=F(t)$

where $M$ is the total mass associated with the structural element, $c$ is the viscous damping constant, $K$ is the stiffness of structural element at the point of maximum deflection, and $\ddot{y}(t)$, $\dot{y}(t)$ and $y(t)$ are acceleration, velocity and displacement of the ESDOF system, respectively. The total blast load on the tributary blast area is applied to the ESDOF system, and it is $F(t)$. The damping is usually neglected for blast analysis since the structure reaches its maximum deflection in a very short time, in which the damping has negligible effects on the peak displacement. For the structural elements that the mass and blast load is concentrated at the point of maximum deflection, the ESDOF system described by Equation (1) yields sufficiently accurate results. The error due to actual mass and blast load being distributed over the tributary area is fixed by using load or stiffness transformation factor $K_{L}$ and mass transformation factor $K_{M}$ [5,12]. These transformation factors are commonly referred as Biggs' Factors. The values of these transformation factors are determined so that the ESDOF system and the actual systems will have the same total work and strain and kinetic energies at any given time. The updated equation of motion for the ESDOF system is given as

$\left(K_{M} M\right) \ddot{y}(t)+\min \left[K_{L} K y(t), K_{L} R_{u}\right]=K_{L} F(t)$

where $R_{u}$ is the ultimate resistance capacity of the member. An alternative and convenient way of writing Equation (2) is obtained by denoting the ratio of mass and load transformation factors as $K_{M L}$

$\left(K_{M L} M\right) \ddot{y}(t)+\min \left[K y(t), R_{u}\right]=F(t)$

The values of load and mass transformation factors depend on mass distribution, structural element support conditions, blast load distribution, and deformed shape of structural element (elastic, elastic-plastic, and plastic) under blast loads. The values of transformation factors for simply-supported and clamped beams subjected to uniformly distributed blast load are given in Table-4 $[5,12]$. 
Comparison of Blast Analysis Methods for Modular Steel Structures

Table 4. Transformation factors for simply supported and uniformly loaded beams

\begin{tabular}{|l|c|c|c|l|c|c|c|}
\hline \multicolumn{4}{|l|}{ Clamped beams } & \multicolumn{5}{|l|}{ Simply supported beams } \\
\hline Deflection & $K_{L}$ & $K_{M}$ & $K_{M L}$ & Deflection & $K_{L}$ & $K_{M}$ & $K_{M L}$ \\
\hline Elastic & 0.53 & 0.41 & 0.77 & Elastic & 0.64 & 0.50 & 0.78 \\
\hline Elastic-Plastic & 0.64 & 0.50 & 0.78 & & & & \\
\hline Plastic & 0.50 & 0.33 & 0.66 & Plastic & 0.50 & 0.33 & 0.66 \\
\hline
\end{tabular}

The general equations for computing transformation factors are given by Biggs $[10,12]$ as

$K_{M}=\frac{\int_{0}^{L} m \emptyset^{2}(x) d x}{m L}$

$K_{L}=\frac{\int_{0}^{L} w \emptyset(x) d x}{w L}$

where $L$ and $m$ are beam span length between the supports and mass of the beam, respectively; $w$ is the distributed static load that has the same distribution as the blast load, and $\phi$ is the assumed-shape function for the beam deflection when it is subjected to the blast. The shape function is in fact the deflected shape of the beam, where the maximum deflection is set to be unity. Because the shape of deflection curve changes depending on the deflection being elastic, elastic-plastic or plastic, the values of transformation factors change accordingly as given in Table-4. However, in practice it is common to use a constant value for the transformation factors throughout the analysis. The appropriate values depend on the predominant displacement response of the structural member. In the following section, the details of prototype building roof joist and plate ESDOF systems are given as sample cases.

\section{The ESDOF system for prototype building roof joists}

The roof joists (W4x13) span length $(L)$ is $2.9 \mathrm{~m}$ and its tributary area for blast loading and mass calculation is $0.8 \mathrm{~m}$, which is the nominal spacing between the joists. The section selfweight $(W) 190 \mathrm{~N} / \mathrm{m}$, moment of inertia about strong axis $\left(I_{x}\right) 4703415 \mathrm{~mm}^{4}$, strong axis plastic section modulus $\left(Z_{x}\right) 102911 \mathrm{~mm}^{3}$, and modulus of elasticity $(E) 200000 \mathrm{MPa}$ were obtained from AISC steel construction manual [14]. The section dynamic yield stress values are $452 \mathrm{MPa}$ and $425 \mathrm{MPa}$ for bending/shear and axial stresses, respectively as given in Table-3. For the blast analyses performed, the bending dynamic yield stress value ( $452 \mathrm{MPa})$ was used since the main response of the joists will be in bending rather than axial deformations. The boundary conditions for the joist were assumed to be fixed on both ends. For beams with fixed ends and subjected to uniform distributed load, the plastic hinges form first at the supports, and as the load increases a third plastic hinge forms at the mid-span as shown in Figure-8 and 9. 


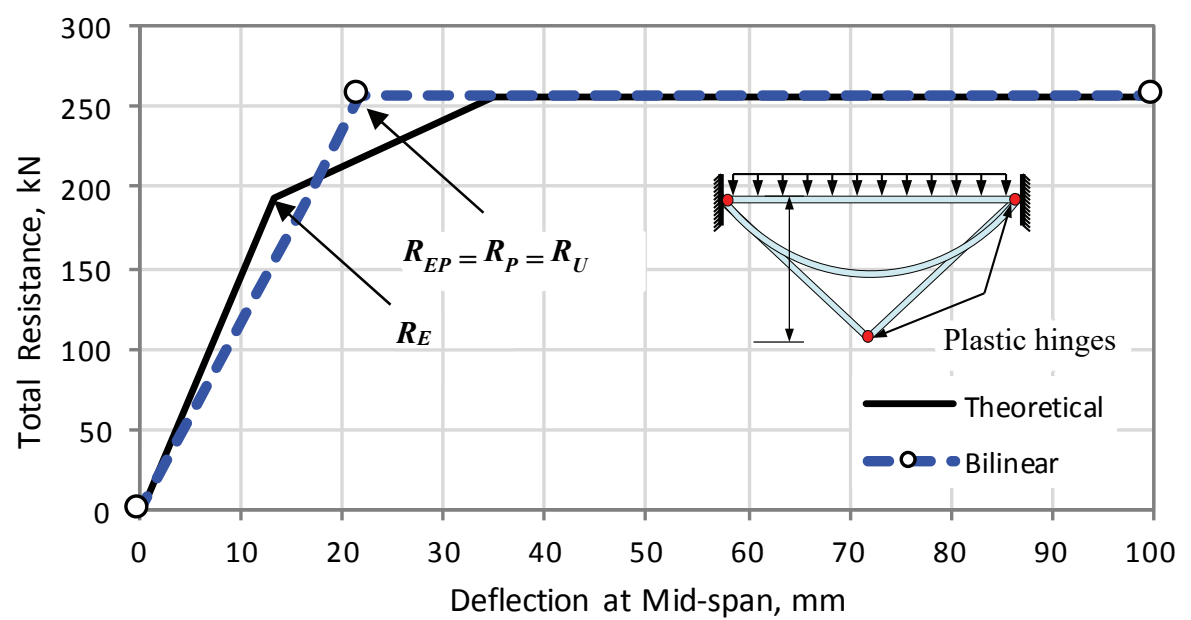

Figure 9. Roof joists resistance-curves

The beam load versus displacement curve (resistance-curve), which is needed to define the spring resistance for the ESDOF system, has three regions namely elastic, elasto-plastic, and plastic regions as given in Figure-9. The stiffness equations for mid-span deflection (location of maximum deflection) of the beam for each region are given as

$K= \begin{cases}K_{E}=384 E I_{x} / L^{3}, & \text { elastic } \\ K_{E P}=384 E I_{x} / 5 L^{3}, & \text { elasto-plastic } \\ K_{P}=0, & \text { plastic }\end{cases}$

The stiffness values $K_{E}$ and $K_{E P}$ are $14.81 \mathrm{kN} / \mathrm{mm}$ and $K_{E P} 2.96 \mathrm{kN} / \mathrm{mm}$, respectively. Resistance values, which are needed to define the resistance-curve are given as

$R= \begin{cases}R_{E}=12 M_{P S} / L, & \text { elastik } \\ R_{E P}=8\left(M_{P C}+M_{P S}\right) / L, & \text { elasto-plastic } \\ R_{P}=8\left(M_{P C}+M_{P S}\right) / L, & \text { plastic }\end{cases}$

where $R_{E}, R_{E P}$, and $R_{P}$ are the elastic, elasto-plastic, and plastic resistance capacities of the roof joists for the given blast load distribution, and $M_{P C}$ and $M_{P S}$ are the ultimate moment capacity of the section at mid-span and supports, respectively. Because the section of the joists is constant along its span, $M_{P C}$ and $M_{P S}$ are equal and given as the product of plastic section modulus and dynamic yield stress $\left(Z_{x} F_{d y}\right)$. In general, the resistance-curves are assumed to be bilinear (elastic-perfectly plastic) to simplify dynamic analysis as shown in Figure-9. The stiffness of elastic part of the bilinear curve is called effective stiffness $\left(K_{E Q}\right)$, and it is selected so that the areas under the actual and bilinear resistance-curves are equal. The effective stiffness of the roof joist is given as $307 E I_{x} / L^{3}$, and it corresponds to an elastic stiffness of $11.84 \mathrm{kN} / \mathrm{mm}$ for the joists. 
The last parameters that are needed for the ESDOF system are the mass associated with the joist and the initial static load (self-weight) carried by the joist. The dynamic mass of joist is $146.7 \mathrm{~kg}$, and it includes $56.2 \mathrm{~kg}$ of joist self-mass and $90.5 \mathrm{~kg}$ for roof plate mass over the joist tributary area. Therefore, the initial static load associated with this mass and carried by the joist is $1439 \mathrm{~N}$. The theoretical and bilinear deflection versus resistance-curves for the roof joist are given in Figure-9. The bilinear curve with $K_{E Q}=11.84 \mathrm{kN} / \mathrm{m}$, ultimate resistance $R_{u}=256.6 \mathrm{kN}$, transformation factor $K_{M L}=0.78$, and mass of $146.7 \mathrm{~kg}$ were used for the joist ESDOF system.

\section{The ESDOF system for prototype building roof plate and crimped wall panels}

Roof and wall plates load versus deflection relationship (i.e., resistance-curves) need to be established to develop the corresponding ESDOF systems. Because the panels are only $5 \mathrm{~mm}$ in thickness, the blast load applied perpendicular to their planes is carried primarily by the membrane action rather than the bending action. Although there are readily available tables and closed form equations for predicting load versus deflection relationship for flat plates, such tools typically ignore the membrane action, and they do not exist for crimped wall panels. Therefore, the resistance-curves for the panels were developed using local 3D FE models to capture effects of membrane action and geometric nonlinear behavior. Moreover, using FE local model to establish plate's ESDOF resistance-curves minimizes analysis errors associated with the resistance-curve. The developed local roof panel model had a span length equal to the spacing between the roof joists and a width equal to half of its span length. The edges of the panel supported by the roof joists were assumed to be fixed (restrained for all degrees of freedom) along the panel width, and free support condition (all degrees of freedom released) was assumed for other two edges along the span length. The assumed boundary conditions are compatible with the roof panels acting as one-way slab between the roof joists.

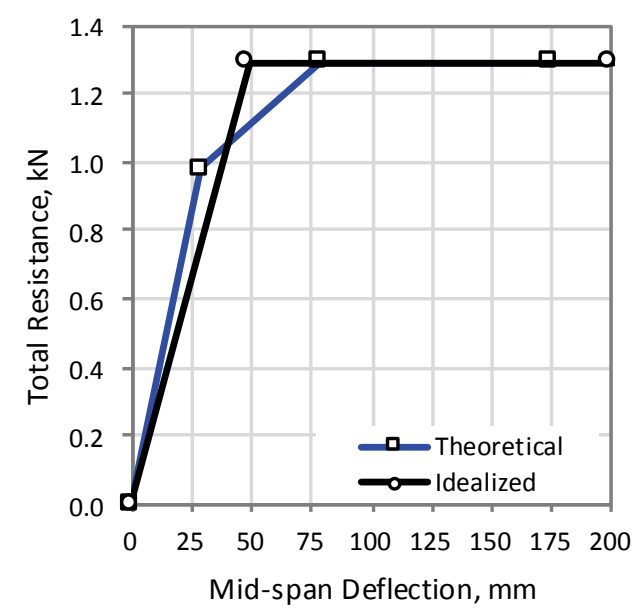

(a)

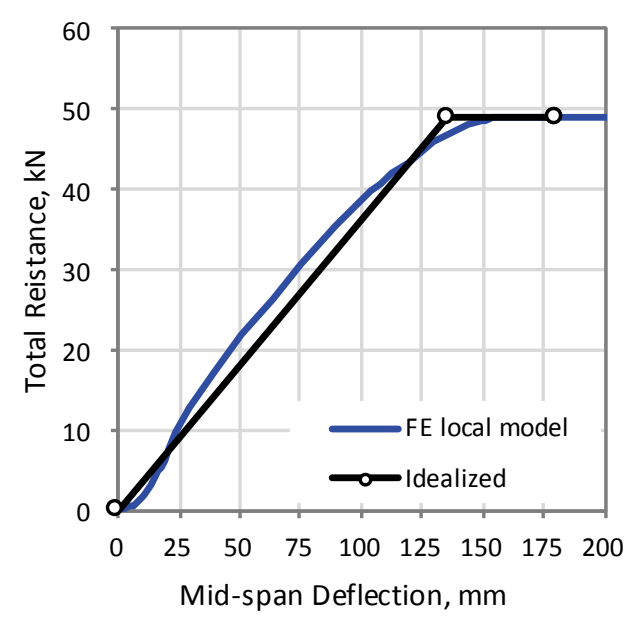

(b)

Figure 10. Resistance-curves for roof plate (a) bending mechanism only (b) bending plus membrane mechanisms 
The theoretical and idealized load versus displacement curves per $25 \mathrm{~mm}$ roof panel width are given in Figure-10 for cases with and without membrane action. The results show that roof plate carries the blast load mainly by the membrane action as expected, and the bending mechanism has negligible contribution to plate's resistance. In addition to the ESDOF, two FE models were used to evaluate blast performance of the roof panels. These are the FE prototype building model, where the entire building was modeled, and the local FE model used to determine roof panels resistance-curve. For the crimped wall panels, developing the resistance-curve is challenging due to trapezoidal cross-section and geometric nonlinearity. Therefore, the resistance-curve for the crimped wall panels given in Figure-10 was established by loading a local FE model of the entire wall panel spanning between the columns and floor and roof beams under uniformly distributed static load.

\section{RESULTS AND DISCUSSSION}

Maximum deflection, the corresponding Von-Mises stresses and effective plastic strain (PEEQ) for the prototype building are shown in Figure 11 and 12 for blast loads BL-50 and BL-80, respectively. For low damage level blast loading BL-50, the crimped wall panel facing direct blast loading developed plastic hinges in the vicinity of its connection to the floor and roof beams as well as at its mid-span. However, the stress levels remained below the yielding for other wall and roof plates due to much smaller blast load acting on them. Yielding in the north module roof joists occurred at their north supports only, while yielding in the south module joists occurred at their mid-span only as shown in Figure-11. In other words, the observed yielding patterns of roof joists in the north and south modules contradict the expected and assumed deformation shape function for the corresponding ESDOF systems. Due to joists having fixed support condition, yielding was expected to occur first over the supports and then at their mid-span. For the main frame beams and columns of the building, yielding occurred only in the middle column facing direct blast loading. Because the connections between the structural members (i.e., full penetration welds) were assumed to be strong enough to develop their full plastic capacity, their full plastic capacity is reached when three plastic hinges (over each support and at the mid-span) are formed. The only structural elements with three plastic hinges are the crimped wall panels facing direct blast loading (Figure-11c). Therefore, building blast damage level is not significant under BL-50 loading and consistent with low damage level.

For high damage level blast loading BL-80, significant yielding was observed for the structural members including wall and roof panels, columns, and roof and floor beams as shown in Figure-12. Especially, the frame members of the north module experienced significant plastic deformation and damage. The roof and floor joists and beams also experienced significant plastic deformations. The roof plate damage was mostly limited to building north module, but the prototype building experienced significant damage overall under BL-80 blast loading, and the observed deflections and damage levels were consistent with high damage level response.

Roof joists deflection histories under blast loads BL-50 and BL-80 are given in Figure-13 for ESDOF and FE analyses. The reported deflections are relative deflections at the point of maximum deflection, and they are corrected for the support deflection. The maximum roof joist displacements computed from the ESDOF and FE analyses were $16 \mathrm{~mm}$ and $30 \mathrm{~mm}$ 


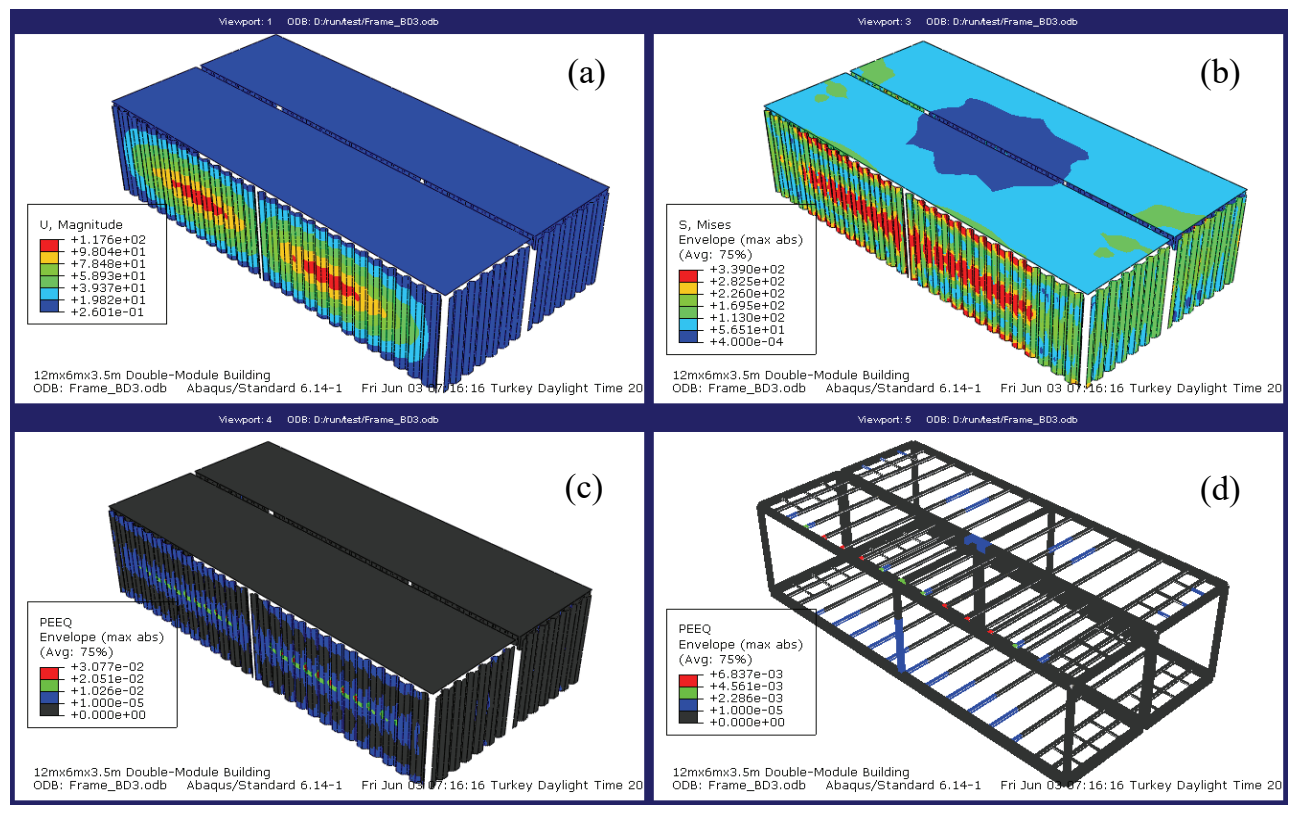

Figure 11. Under blast load BL-50 (a) maximum deflection in wall panels, (b) Von-Mises stresses, and ( $c \& d$ ) effective plastic strain (units in mm and MPA)

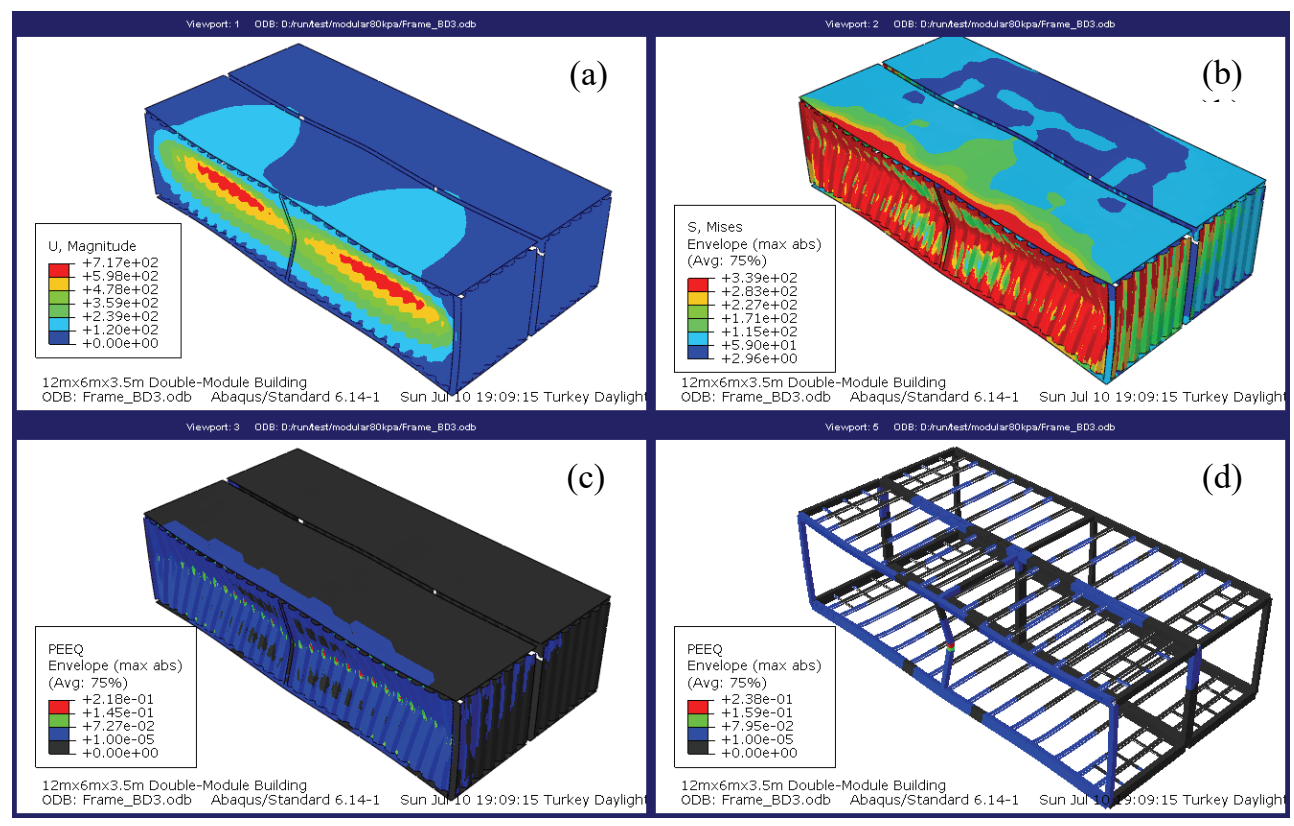

Figure 12. Under blast load BL-80 (a) maximum deflection in wall panels, (b) Von-Mises stresses, and ( $c \& d$ ) effective plastic strain (units in mm and MPA) 
under blast load BL-50 and $26 \mathrm{~mm}$ and $38 \mathrm{~mm}$ under blast load BL-80, respectively. For both blast loads, the roof joist deflection history predicted using the ESDOF analysis was always smaller than that predicted using FE analysis. The maximum roof joist deflections computed using the ESDOF analysis correspond to a ductility of 0.7 and 1.2 for blast loading BL-50 and BL-80, respectively. However, FE analysis results given in Figure-11 and 12 show significant roof joist plastic deformation for both loadings. In other words, the ESDOF blast analysis results are on the unconservative side for the roof joists.

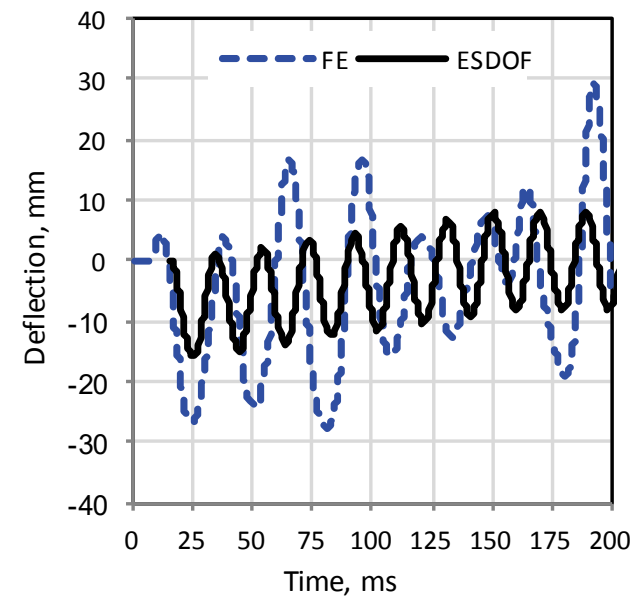

(a)

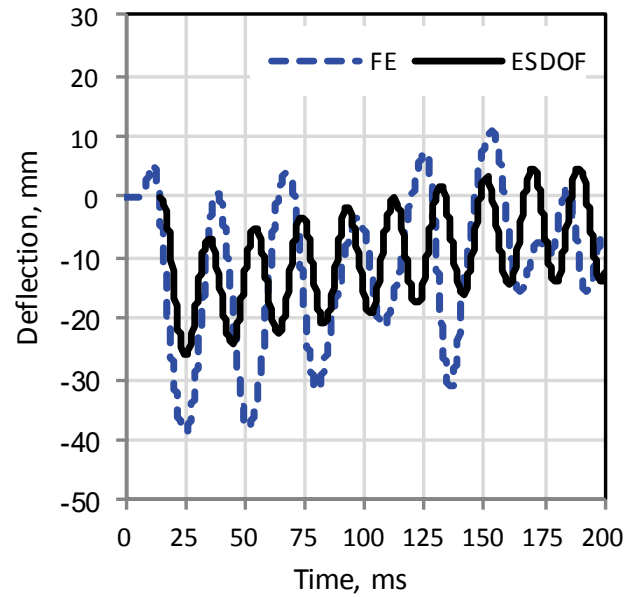

(b)

Figure 13. Displacement versus time histories for roof joists subjected to (a) BL-50 and (b) BL-80 blast loads

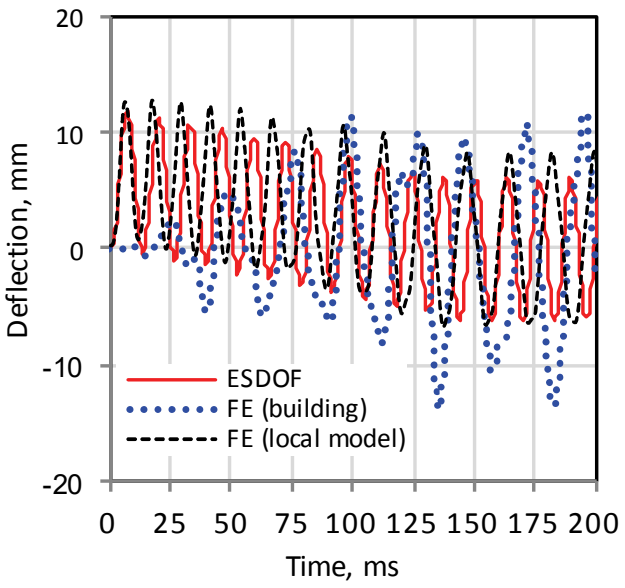

(a)

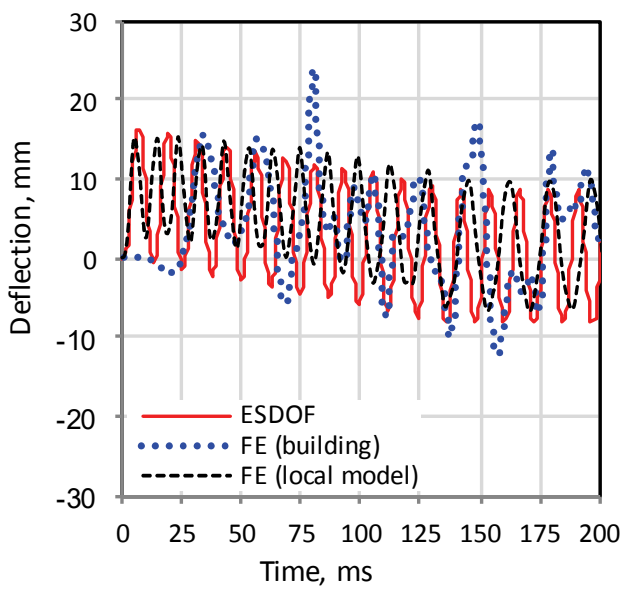

(b)

Figure 14. Roof plate displacement histories under (a) BL-50 and (b) BL-80 blast loads 
The time versus deflection curves for roof panel calculated using the ESDOF and two FE analyses for blast loads BL-50 and BL-80 are given in Figure-14. In addition to the building FE model, the local roof plate FE model used to develop the ESDOF resistance-curve was also employed for roof plate blast analysis. This local model is useful to further verify the ESDOF analysis results and distinguish the effects of dynamic interactions.

The initial discrepancy between roof plate deflection histories in Figure-14 predicted with the ESDOF and building FE models is due to the time required for the blast wave to reach the location on the roof with the plate maximum deflection. The deflection histories of roof plate predicted with the ESDOF and local FE models exhibit good agreement for both blast loads BL-50 and BL-80 in terms of maximum deflections and vibration periods as shown in Figure-14. Therefore, roof plate ESDOF model is suitable to predict its uncoupled blast performance. However, roof plate FE results indicate that the ESDOF blast analysis results are on the unconservative side mainly due to dynamic interaction of structural members, which is neglected in the ESDOF and local FE analyses. The computed roof plate maximum deflections, which were corrected for the support deflections, under blast load BL-50 were $12 \mathrm{~mm}, 13 \mathrm{~mm}$, and $14 \mathrm{~mm}$ for the ESDOF, plate local FE, and building FE models, respectively. Under blast load $\mathrm{BL}-80$, the roof plate maximum deflections were $17 \mathrm{~mm}, 16$ $\mathrm{mm}$, and $24 \mathrm{~mm}$ from the ESDOF, local FE, and building FE models, respectively.

Table 5. Summary of performance of prototype building members under blast load BL-50

\begin{tabular}{|l|c|c|c|c|c|c|}
\hline \multirow{2}{*}{$\begin{array}{c}\text { Structural } \\
\text { Element }\end{array}$} & Location & \multicolumn{2}{|c|}{$\begin{array}{c}\text { Maximum deflection, } \\
\mathrm{mm} \text { and }(\mu)^{(1)}\end{array}$} & \multicolumn{2}{c|}{$\begin{array}{c}\text { Maximum support } \\
\text { rotation } \theta \text { (degree) }\end{array}$} & $\begin{array}{c}\text { ESDOF } \\
\text { Error (3) } \\
(\%)\end{array}$ \\
\cline { 2 - 7 } & ESDOF & Building FE & ESDOF & Building FE & $(\%)$ \\
\hline Roof joists & Roof & $16(0.7)$ & $30(1.3)$ & 0.3 & 1.2 & -47 \\
\hline Roof strut & Roof & $<1(0.1)$ & $2(1.7)$ & $<0.1$ & 0.5 & -67 \\
\hline Roof plate & $\begin{array}{c}\text { Roof } \\
\text { Top intermediate } \\
\text { long. beam } \\
\text { HSS 8x6x1/2 }\end{array}$ & $60(1.2)$ & $48(1.0)$ & 1.2 & 0.9 & -14 \\
\hline $\begin{array}{l}\text { Top intermediate } \\
\text { transverse beam } \\
\text { HSS 8x6x3/8 }\end{array}$ & $\begin{array}{c}\text { Roof } \\
\text { (column line-2) }\end{array}$ & $2(0.2)$ & $13(1.2)$ & 0.1 & 0.5 & -85 \\
\hline $\begin{array}{l}\text { Column } \\
\text { HSS 6x6x1/2 }\end{array}$ & column line-A\&2 & $30(1.8)$ & $37(2.2)$ & 1.1 & 1.4 & -19 \\
\hline Wall panel & column line-A & $41(1.3)$ & $105(3.3)$ & 2.3 & 5.8 & -61 \\
\hline
\end{tabular}

(1) Ductility $=[($ maximum deflection $/$ ESDOF yield deflection $]$

(2) Support rotation $=$ [(Maximum deflection $) /$ minimum distance to the support from max. deflection point $]$

(3) Error $=[($ ESDOF- Building FE)/ Building FE $] 100$; (applied to maximum deflections) 
Table 6. Summary of performance of prototype building members under blast load BL-80

\begin{tabular}{|c|c|c|c|c|c|c|}
\hline \multirow[t]{2}{*}{$\begin{array}{c}\text { Structural } \\
\text { Element }\end{array}$} & \multirow[t]{2}{*}{ Location } & \multicolumn{2}{|c|}{$\begin{array}{c}\text { Maximum deflection, } \\
\text { mm and } \\
(\mu)^{(1)}\end{array}$} & \multicolumn{2}{|c|}{$\begin{array}{c}\text { Maximum support } \\
\text { rotation } \\
\theta \text { (degree) }^{(2)}\end{array}$} & \multirow[t]{2}{*}{$\begin{array}{c}\text { ESDOF } \\
\text { Error }{ }^{(3)} \\
(\%)\end{array}$} \\
\hline & & ESDOF & Building FE & ESDOF & Building FE & \\
\hline Roof joists & Roof & $26(1.2)$ & $38(1.8)$ & 1.0 & 1.5 & -32 \\
\hline Roof strut & Roof & $<1(0.1)$ & $3(2.5)$ & $<0.1$ & 0.6 & -67 \\
\hline Roof plate & Roof & $17(0.1)$ & $24(0.2)$ & 2.4 & 3.4 & -29 \\
\hline $\begin{array}{l}\text { Top intermediate } \\
\text { long. beam } \\
\text { HSS } 8 \times 6 \times 1 / 2\end{array}$ & $\begin{array}{c}\text { Roof } \\
\text { (column line-B) }\end{array}$ & $194(4.0)$ & $132(2.7)$ & 3.7 & 2.6 & 47 \\
\hline $\begin{array}{l}\text { Top intermediate } \\
\text { transverse beam } \\
\text { HSS } 8 \times 6 \times 3 / 8\end{array}$ & $\begin{array}{c}\text { Roof } \\
\text { (column line-2) }\end{array}$ & $4(0.4)$ & $31(2.8)$ & 0.2 & 1.2 & -87 \\
\hline $\begin{array}{l}\text { Column } \\
\text { HSS } 6 \times 6 \times 1 / 2\end{array}$ & (column line-A\&2) & $375(22)$ & $396(23)$ & 13.8 & 14.6 & -5 \\
\hline Wall panel & (column line-A) & $198(6.2)$ & $665(20.1)$ & 10.8 & 32.6 & -70 \\
\hline
\end{tabular}

Blast performance of other structural members of the prototype building predicted using the ESDOF and building FE analyses are given in Table- 5 and Table- 6 for blast loads BL-50 and BL-80, respectively. The results show that blast performance of the prototype building (i.e., deflection, ductility, support rotation) predicted with the ESDOF method were on the unconservative side by $19 \%$ to $85 \%$ for the blast load BL-50 and by $5 \%$ to $87 \%$ for the blast load BL-80. The only exception was the top intermediate longitudinal beam, of which blast performance was over predicted by $25 \%$ and $47 \%$ in terms of maximum deflection using the ESDOF analysis. This main roof beam is supporting the roof joists and plate, and it is connected to the adjacent building module through the roof plate. Therefore, the dynamic interaction of this beam with the rest of the structure is complicated, and this interaction is considered to be significant on its dynamic response.

The main reason for the ESDOF blast analysis results of the prototype building being on the unconservative side is the inherent assumption that members' dynamic interaction does not affect their dynamic response. The accuracy of the ESDOF depends on how well the deformed shape of the element is predicted and blast loads are applied. The dynamic interaction affects the member behavior by changing the assumed deformed shape for the ESDOF analysis and consequently affecting the values of Biggs' transformation factor and location and sequence of plastic hinge formation. For example, in the ESDOF analysis of roof joists, the support condition was assumed to be fixed, and Biggs' transformation factors were accordingly determined. However, the effective plastic strain (PEEQ) counters in Figure 11 and 12 show that plastic hinges formed at only one end of the joists over the support 
under blast load BL-50. However, the assumption of fixed-end support condition for the joists requires formation of two plastic hinges over the two supports at the same time. Therefore, the observation shows that dynamic interaction between the roof joist and other members affects roof joists' support condition and their shape function. A similar observation can be done for the intermediate column on the north wall under blast load BL-80. For the ESDOF analysis, the boundary condition was assumed to be fixed for two ends, and therefore the assumed deformed shape is based on formation of plastic hinges over the supports and then at the mid-span. However, the effective plastic strain counters given in Figure 11 and 12 show that yielding occurred over the column base support and mid-span while the rest of the column remained elastic including the top support region.

\section{SUMMARY, CONCLUSIONS AND RECOMMENDATIONS}

In this study, the blast performance of a two-module blast-resistant modular steel-framed building was determined in terms of deflection, ductility, and support rotation demands using uncoupled equivalent single degree of freedom (ESDOF) and detailed 3D finite element (FE) blast analysis methods. Two blast loads corresponding to building "low damage" and "high damage" response levels were considered. The blast loads prescribed for the building in terms of free field overpressure and duration were converted into local pressure loads for the building walls and roof to investigate effects of dynamic interaction of structural members under blast loading. The developed building FE model included effects of dynamic interaction of structural members, blast load distribution within the structural elements, and structural mass distribution as well as initial static load to due to gravity. On the other hand, the ESDOF analysis method is an approximate dynamic approach based on the assumption that the dynamic interaction of the structural members can be neglected, and their dynamic behavior can be represented with simple spring-mass models. Although the ESDOF blast analysis method is widely used in blast analysis, a detailed verification of the approach including dynamic interaction of structural elements is not available.

Based on the analysis results presented for the structural members of the building under the given blast loads, the following conclusions are made:

- The ESDOF blast analysis method is a powerful simple tool for predicting blast response of structural members. However, the ESDOF blast analysis is an approximate analysis method with the basic assumption that dynamic interaction of interconnected structural elements can be neglected.

- The accuracy of ESDOF analysis depends on engineering judgment needed to estimate structural member deformed shape, mass, tributary blast area, and its resistance-curve for the considered blast loads.

- The predicted blast damage levels (maximum deflections) for the prototype building structural members with the ESDOF analysis were on the unconservative side by $19 \%$ to $85 \%$ for the blast load BL-50 and by $5 \%$ to $87 \%$ for the blast load BL- 80 compared to those predicted using building detailed FE model. Therefore, dynamic interaction of structural members is significant, and it should not be neglected. This finding contradicts with the literature; however the studies considering the ESDOF analysis being conservative are limited to the studies performed with limited 
parameters in terms of the number of structural members dynamically interacting (typically a main beam supported by two beams at supports), boundary conditions, and blast loading.

- The dynamic interaction of structural members affects the member blast performance by changing the assumed deformed shape for the ESDOF analysis and consequently affecting the values of Biggs' transformation factors and location and sequence of plastic hinge formation.

The following recommendation can be made based on the results and findings presented:

- ESDOF blast analysis is an approximate method requiring crucial engineering judgment regarding the expected deformed shape, boundary conditions, mass, and blast loads. Sufficient accurate results can be obtained where the dynamic interaction of structural members is negligible. However, for the cases that dynamic interaction is significant or high accuracy results are needed, more sophisticated finite element tools including member dynamic interaction effects should be used.

- The ESDOF blast analysis method is a powerful tool to determine blast performance of structural members. It is especially recommended at the preliminary design stage to determine size of structural members. However, there is a need for additional studies to incorporate the dynamic interaction of structural members in the ESDOF blast analysis method.

\section{Symbols}

c : Viscous damping constant

$F \quad$ : Dynamic blast load

$F_{d y} \quad:$ Dynamic yield stress

$F_{u} \quad$ : Minimum tensile strength

$F_{y} \quad:$ Static yield stress

$I_{x} \quad$ : Moment of inertia about strong axis

$K \quad$ : Spring stiffness

$K_{E} \quad$ : Member stiffness for elastic region

$K_{E P}:$ Member stiffness for elasto-plastic region

$K_{L} \quad$ : Load or stiffness transformation factor

$K_{M} \quad$ : Mass transformation factor

$K_{M L} \quad: \quad$ The ratio $K_{L} / K_{M}$

$K_{P} \quad$ : Member stiffness for plastic region

$K_{E Q} \quad$ : Effective stiffness

$L \quad$ : Member span length

$m \quad$ : Mass per length

$M \quad$ : Total dynamic mass

$M_{P C} \quad$ : Ultimate moment capacity at midspan 


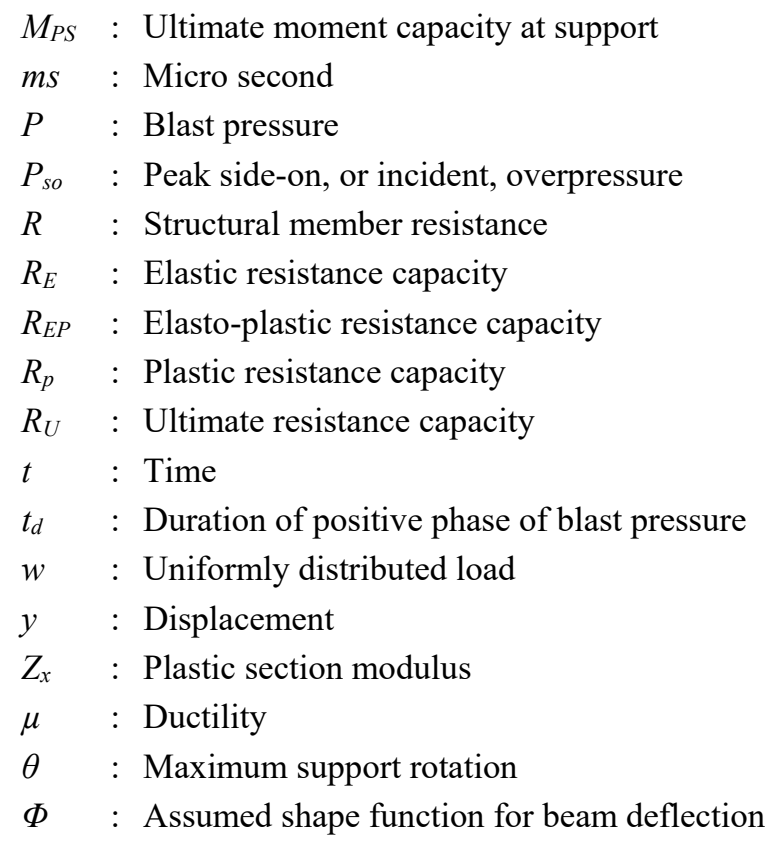

\section{References}

[1] "Reference Manual to Mitigate Potential Terrorist Attacks against Buildings (FEMA 426)," Washington, D.C., 2003

[2] "Primer for Design of Commercial Buildings to Mitigate Terrorist Attacks (FEMA 427)," Washington, D.C., 2003.

[3] Ngo T., Mendis P., Gupta A., and Ramsay J., "Blast Loading and Blast Effects on Structures - An Overview," Electronic Journal of Structural Engineering, Special Issue: Loading on Structures, 7, 76-91, 2007.

[4] Comert M., and Ilki A., "The Explosion Performance of a Ball Powder Production Facility,” Journal of Performance of Constructed Facilities, 24, 326-336, 2010.

[5] "Design of Blast Resistant Buildings in Petrochemical Facilities," American Society of Civil Engineers (ASCE), New York, 1997.

[6] Summers P., "Design of Modular Blast-Resistant Steel-Frames Buildings in Petrochemical Facilities," Structures Congress, Vancouver, Canada, 2008

[7] "Methodology Manual for the Single-Degree-of-Freedom Blast Effects Design Spreadsheets," U.S. Army Corps of Engineer, Omaha, 2008.

[8] Krauthammer T., "Blast Mitigation Technologies: Developments and Numerical Considerations for Behavior Assessment and Design," Proceedings of International Conference on Structures under Shock and Impact, Computational Mechanic Publications, Southampton, 1998. 
[9] Conrath E. J., Krauthammer T., Marchand K. A., and Mlakar P. F., Structural Design for Physical Security: State of the Practice, American Society of Civil Engineers, Reston, Virginia, 1999.

[10] Yokoyama T., "Verification and Expansion of Single-Degree-of-Freedom Transformation Factors for Beams using a Multi-Degree-of-Freedom Non-Linear Numerical Analysis Method," MS Thesis, California Polytechnic State University, 2011.

[11] Lawver D., Daddazio R. Vaughan D., Stanley M., and Levine H., "Response of AISC Steel Column Sections to Blast Loading," ASME Pressure and Vessels and Piping Conference, Cleveland, Ohio, 2003.

[12] Biggs J.M., Introduction to Structural Dynamics, McGraw-Hill, New York, 1964.

[13] Baker W. E., Cox P.A., Westine P.S., Kulesz J.J., and Strehlow R.A., Explosion Hazard and Evaluation, Elsevier, Amsterdam, Netherlands, 1983.

[14] "Specification for Structural Steel Buildings (AISC 360-10)," American Institute of Steel Construction, Chicago, Illinois, 2010.

[15] "Seismic Provisions for Structural Steel Buildings (AISC 341-16)," American Institute of Steel Construction, Chicago, Illinois, 2016

[16] "Structures to Resist the Effects of Accidental Explosions, Army TM 5-1300, Navy NAVFAC," U.S. Department of the Army, Washington, DC., 1990.

[17] Committee for the Prevention of Disasters Due to Dangerous Substances, "TNO Green Book, Method for the Determination of Possible Damage to People and Objects Resulting from Releases of Hazardous Materials (CPR 16E)," The Director-General of Labor, Netherlands, 1992.

[18] Feldgun V. R., Yankelevsky D., and Karinski Y.S., "Study of the Blast Response of Beams and Thin Rectangular Plates Using a Nonlinear SDOF Model," the $16^{\text {th }}$ ISIEM, Destin, FL, 2015. 
